\title{
Intersecção entre a Lei de Acesso à Informação e a avaliação de tecnologias em saúde
}

\author{
Intersection between the Information Access Law and Health Technology Assessment
}

\section{Gabriela Vilela de Brito}

Farmacêutica, Especialista em Farmacologia Clínica e Vigilância Sanitária. Coordenação-Geral de Avaliação de Tecnologias em Saúde/ Departamento de Ciência e Tecnologia/ Secretaria de Ciência, Tecnologia e Insumos Estratégicos/ Ministério da Saúde. Brasília, Brasil.

\section{Júlia Souza Vidal.}

Farmacêutica, Especialista Vigilância Sanitária e Mestranda em Saúde Coletiva. Coordenação-Geral de Avaliação de Tecnologias em Saúde/ Departamento de Ciência e Tecnologia/ Secretaria de Ciência, Tecnologia e Insumos Estratégicos/ Ministério da Saúde. Brasília, Brasil.

Resumo: A Lei de acesso à informação tem modificado a percepção social quanto à propriedade e distribuição da informação, ao conferir autonomia e empoderamento individual. Atribuiu maior aplicabilidade ao direito elencado no art. 5, XXXIII, da Constituição Federal e estimulou participação, compromisso, motivação e corresponsabilização sociais. Ademais, fortaleceu a democracia brasileira, visto que a proteção às liberdades civis, na qual o direito de acesso à informação se assenta, é precondição necessária de todo governo democrático. No tocante a tecnologias em saúde, é necessário associá-las à informação e à comunicação, para promover geração, transmissão, sustentabilidade e evolução compartilhada do conhecimento. A Avaliação de Tecnologias em Saúde (ATS) avalia a evidência disponível e auxilia os diferentes atores a compreender o desenvolvimento, a difusão e o uso apropriado delas. Assim, é um acesso a informações úteis e confiáveis, que auxilia na formulação e definição de políticas de saúde. Considera não apenas os aspectos técnicos, mas também a avaliação do impacto de implantação de uma tecnologia sobre uma população, tanto do ponto de vista ético quanto social. No Brasil, esta cultura ainda é incipiente e necessita aprimorar os aspectos culturais e ambientais em suas análises e a percepção dos usuários no processo. O acesso à informação é fundamental para o processo educativo do homem, um fator determinante da saúde, que representa direito à formação pessoal e permite extensão da participação do cidadão. Nesse sentido, a Lei de Acesso à Informação fortalece o papel da ATS de fornecer informações sólidas e transparentes aos interessados.

Palavras-chave: acesso à informação pública; Avaliação de Tecnologias em Saúde; Sistema Único de Saúde; participação social.

Key-words: access to public information; Health Technologies Assessment; Brazilian Public Health System; social participation 


\section{0 contexto e análise da lei}

A Constituição Federal de 1988, em seu artigo $5^{\circ}$, inciso XXXIII, assegura a todos o direito a receber dos órgãos públicos informações de seu interesse particular, coletivo ou geral, que serão prestadas no prazo da lei, sob pena de responsabilidade, ressalvadas aquelas cujo sigilo seja imprescindível à segurança da sociedade e do Estado. A regulamentação desse direito ocorreu inicialmente com a Lei $n^{0} 11.111$, de 2005, revogada pela Lei de Acesso à Informação (LAI - Lei no 12.527, de 2011), com texto legal mais claro e específico, regulamentando também o inciso II do $\S 3^{\circ}$ do art. 37 e o $\S 2^{\circ}$ do art. 216 da Constituição Federal (Brasil, 1988; Brasil, 2011b).

A iniciativa está em consonância com o disposto em diversos instrumentos internacionais de direitos humanos, os quais reconhecem e consagram o acesso à informação como um direito fundamental de todos os indivíduos. Essa é uma tendência mundial e, nos últimos anos, inúmeras leis de acesso à informação foram editadas em diversos países, com objetivo de fortalecer a transparência dos governos e garantir às pessoas o acesso a dados detidos pelo Estado. Ademais, esse movimento reconheceu-a como elemento imprescindível ao desenvolvimento humano sustentável e à prestação de contas (Canela; Nascimento, 2009).

No Brasil, com o advento da LAI, fica assegurado o acesso a informações de interesse particular, coletivo ou geral, e a registros administrativos e a dados sobre atos de governo, cabendo à Administração Pública a gestão da documentação governamental e as providências para franquear sua consulta a quantos dela necessitarem. Assim, trata-se de direito individual e difuso, já que resulta em benefícios à coletividade em geral.

Com a Lei, foi incorporada à Administração Pública uma cultura de acesso aberto, na qual a circulação de informações deixa de ser considerada um risco, e o sigilo passa a ser percebido como exceção à regra de divulgação (Brasil, 2011a). Nesse contexto, o Estado torna-se, de fato, um aparato da Administração Pública (Habermas, 2002).

$\mathrm{Na}$ cultura de acesso aberto, reconhece-se que informações públicas pertencem aos cidadãos, o que legitima a demanda e confere-lhes autonomia e empoderamento.

A autonomia conferida aos cidadãos refere-se à possibilidade que têm de solicitar informações sem a necessidade de justificativa, seja por meio de busca das 
informações nas páginas eletrônicas dos órgãos e entidades governamentais, seja pela solicitação ativa aos serviços de informação ao cidadão. Uma forma de liberdade. Por empoderamento compreende-se a emancipação do indivíduo que, quando informado, por canais de comunicação eficientes, conforme discriminado pela LAl, é capaz de transformar relações sociais, culturais, econômicas e de poder, já que muitos direitos e garantias da população relacionam-se com o direito de acesso a informações públicas (Artigo 19, 2013). Como aponta o Artigo 19, associação coordenada com a Article XIX - organização internacional de direitos humanos:

o acesso à informação pública protege direitos humanos e de trabalhadores, promove a saúde (ao dar aos cidadãos informações detalhadas sobre produtos e práticas saudáveis ou perigosas), fortalece a economia (pois empresas podem demandar informações sobre políticas do governo para tomarem decisões) e ajuda a preservar o meio-ambiente (já que permite aos cidadãos identificar ações de governantes com potencial de gerar poluição e reduzir recursos naturais).

Além dos benefícios setoriais, exemplificados acima, decorrentes da disseminação de informações públicas, há que se destacar que o princípio da informação decorre do da liberdade e propicia a melhora na gestão da res publica.

O fornecimento dessas informações está atrelado a transparência, central para o entendimento de boa governança, e accountability. O conceito de transparência envolve ações de visibilidade e acessibilidade às informações e ações governamentais, com vistas a disponibilizá-las de forma útil e confiável à sociedade. Requer um fluxo oportuno de informações que objetive facilitar a compreensão e os mecanismos de accountability. Esta compreende a responsabilização dos gestores por suas ações e pelo uso de recursos públicos: obrigação de se abrir ao público, obrigação de se explicar e justificar suas ações e subordinação à possibilidade de sanções (Angélico, 2012). Do ponto de vista do cidadão, accountability relaciona-se à habilidade dos representados de exigirem respostas de seus representantes sobre intenções e comportamento, de avaliá-los e impor sanções nos casos em que a conduta seja considerada insatisfatória (Canela; Nascimento, 2009). 
Gráfico 1. Diagrama de causa e efeito de Ishikawa.

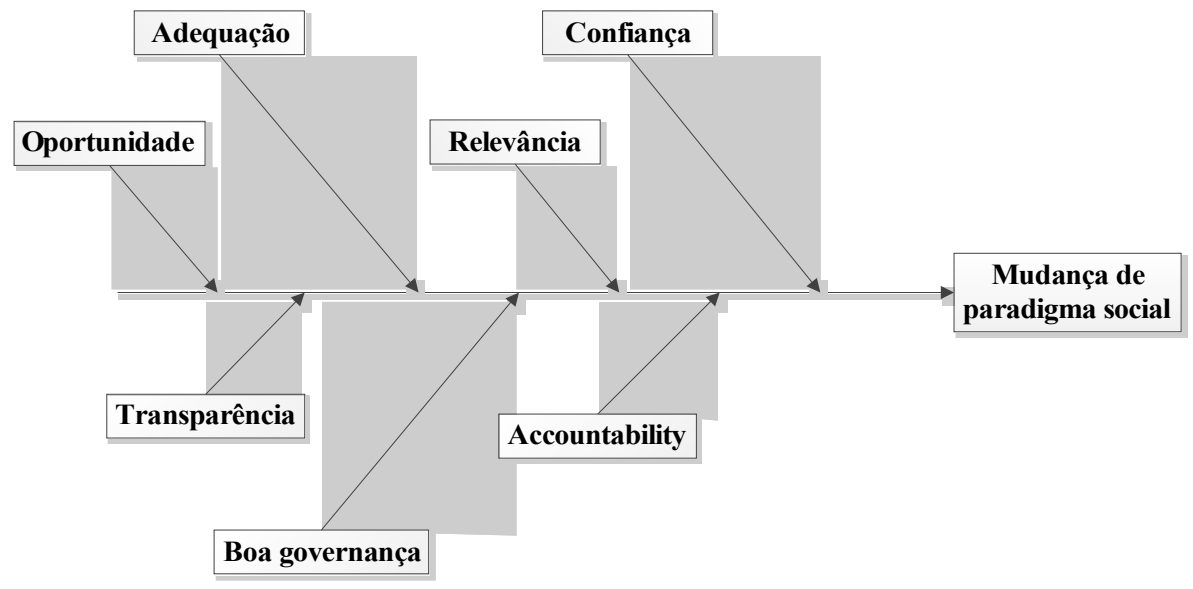

Immanuel Kant já afirmava que todas as ações relativas ao direito dos homens cuja máxima não fosse suscetível de se tornar pública eram, por si só, injustas. Sob tal perspectiva infere-se que a exigência de publicidade dos atos do governo é importante não apenas para permitir ao cidadão conhecer os atos de quem detém o poder e os domina, mas também porque a publicidade é uma forma de controle, um recurso que permite distinguir o que é licito do que não é (BOBBIO, 1992). Uma forma de os cidadãos, membros do Estado, controlarem se o poder estatal está sendo exercido em favor de seus interesses na própria sociedade. Assim, é o direito positivo que convalida o exercício do poder político da coletividade. De acordo com Habermas (2002), é o poder gerado comunicativamente em meio à práxis de autodeterminação dos cidadãos do Estado e que se legitima pelo fato de defender essa mesma práxis por meio da institucionalização da liberdade pública.

Nesse sentido, Bobbio (1992) traz que o Estado liberal é pressuposto histórico e jurídico do Estado democrático, constituindo os direitos à base dos quais nasceu o Estado Liberal e foi construída a doutrina do Estado de direito. Tal interdependência caracteriza-se pelo fato de que esses direitos são o pressuposto necessário para o correto funcionamento dos mecanismos predominantemente procedimentais que materializam um regime democrático.

Assim, uma sociedade democrática caracteriza-se por ter vários centros de poder, por isso é uma esfera pública pluralista, policrática e de força centrífuga, em que a arquitetônica liberal do Estado e da sociedade é fortalecida. Segundo Habermas (2002), ao lado da instância hierárquica reguladora do poder soberano 
estatal e da instância reguladora descentralizada do mercado, surge também a solidariedade (a fraternité da revolução francesa) como uma fonte de integração social.

A legitimidade da autonomia dos cidadãos instituída pelo marco jurídico da LAI estimula: a participação, o compromisso, a motivação e a corresponsabilização do usuário nas decisões. Uma possibilidade de coexistência equitativa dos direitos à comunicação e à participação política no poder administrativo do aparato estatal (Habermas, 2002). Logo, a LAI reforçou um conceito contemporâneo de participação social, o empoderamento. Essa forma de participação social nas decisões cotidianas promove espaços democráticos de controle; a qual não se restringe a abertura de arenas, mas contempla o fornecimento de mecanismos sólidos de compreensão e interpretação da realidade para propiciar transformações efetivas. Uma mudança de paradigma social que contempla a diversidade de formas comunicativas na política deliberativa. Com renovação social gradual, repleto de debates de ideias e mudanças de mentalidades e manifestações, permitindo a formação e a expansão de verdadeiras silentes revoluções (Bobbio, 1992).

Desde a institucionalização do Sistema Único de Saúde (SUS), a participação popular vem sendo um dos pilares da sua organização, efetivado principalmente por arenas conquistadas pelo reconhecido movimento sanitário, num contexto de transição político-social e econômica que destacou a importância do processo democrático na saúde. No início, essa participação limitava-se ao envolvimento da sociedade nos Conselhos e Conferências de Saúde, conforme a lei $\mathrm{n}^{\circ}$ 8.142, de 1990. Entretanto, para garantir, de fato, o caráter universal e integral imputado ao SUS, é mister que se incorpore a participação de atores empoderados na formulação, fiscalização, execução e manutenção de políticas de saúde, visão em consonância com a ideologia da LAI. Depreende-se que a cultura de acesso aberto somada a participação do cidadão aproxima os atores sociais e potencializa a implementação de políticas públicas, desde seu planejamento até sua execução e avaliação (Canela; Nascimento, 2009).

Segundo Moroni (2009), falar de participação de atores empoderados é falar de controle social, o que abrange a participação ativa nos rumos da vida pública para além do já consolidado direito à representação. Isso perpassa a ideia de democracia representativa, de cidadania ativa (activae civitatis) e a mera atitude passiva do 
Estado de fornecer informação à sociedade civil. Surgiria, então, a educação para a democracia no próprio exercício da prática democrática, com retroalimentação do poder administrativo a partir do poder comunicativo decorrente do processo de formação de opinião e vontade política horizontal por meio da liberdade à informação (Bobbio, 1992; Habermas, 2002). Ademais, o desenvolvimento do controle social da Administração Pública é uma das diretrizes da LAI.

Esse movimento ativo da sociedade, demandar o sistema, provoca a percepção por unidades gestoras da importância do envolvimento do usuário. Para essa interlocução é necessário adaptar a linguagem para que se disseminem informações compreensíveis e, de fato, úteis à sociedade.

A Lei Orgânica da Saúde já previa o direito à informação em duas vertentes: o de informação sobre sua saúde às pessoas assistidas por serviços públicos e privados que integram o SUS; e o de divulgação de informação quanto ao potencial dos serviços de saúde e a sua utilização pelo usuário, compreendendo também as informações epidemiológicas que estão sob a responsabilidade dos órgãos públicos (Aith, 2007).

\section{0 papel da avaliação de tecnologias em saúde}

A avaliação de tecnologias em saúde - ATS - é uma especialidade multidisciplinar que apresenta como propósito avaliar a evidência disponível e elaborar informes para auxiliar os gestores, profissionais da saúde e pacientes a entender o valor relativo das tecnologias em saúde ${ }^{1}$ (Jonsson; Banta, 1999; Gabbay, 2006). Nesse sentido, a ATS avalia a segurança, a eficácia, a efetividade (os benefícios e a ausência de danos para os pacientes) e os custos dessas e, em alguns casos, realiza a avaliação do impacto de implantação, tanto do ponto de vista ético quanto social. Para tanto, aplica um método científico sistemático com o propósito intrínseco de obter informação útil, acessível e de fácil utilização para guiar o processo de tomada de decisão baseada em evidências ${ }^{2}$ no mundo real. (Velasco-

\footnotetext{
${ }^{1}$ A Rede Internacional de Agências de Avaliação de Tecnologias de Saúde (INAHTA) conceitua tecnologia em saúde como as intervenções que podem ser utilizadas para promover a saúde e prevenir, diagnosticar, tratar, reabilitar ou cuidar de doenças. Portanto, inclui medicamentos, dispositivos, procedimentos, sistemas de organização e suporte dentro dos quais se fornece o atendimento.

${ }^{2}$ Segundo Drummond (2008), o conceito de tomada de decisão baseado em evidência representa o processo de avaliação rigorosa sobre a magnitude da validade, confiabilidade e aplicabilidade das intervenções sanitárias. Essa avaliação baseia-se nos resultados de investigações disponíveis
} 
Garrido, 2005). Logo, o crescimento e o desenvolvimento da ATS refletem a demanda por informação confiável, sólida e transparente que respalde a tomada de decisão sobre produção, incorporação e difusão de tecnologias em saúde e o direcionamento eficiente dos recursos.

Para a consecução dos seus objetivos, na ATS, é necessário associar as tecnologias em saúde à informação e comunicação, como forma de promover a geração, a transmissão, a disseminação e a sustentabilidade do conhecimento. Além disso, vai ao encontro da obrigatoriedade da LAI quanto à necessidade de prover informações tempestivas e em linguagem adequada aos usuários e outros interessados nas ações e serviços de saúde, como os gestores das três esferas de gestão.

No Brasil, a cultura de ATS vem sendo implantada desde meados da década de 2000. Como todo novo propósito, ainda necessita fortalecer alguns de seus papéis, tais como: a inclusão dos aspectos culturais, ambientais, de equidade e a percepção dos usuários no processo. Esse fortalecimento é imprescindível para a integração das dimensões científica (excelência), econômica (sustentabilidade), ética (qualidade dos cuidados) e social (equidade), intrínsecas às ATS.

Os aspectos éticos e sociais ainda estão em fase embrionária no País, no entanto a LAl é um respaldo jurídico que os reinsere nas agendas políticas. Pelo fato de compreenderem o indivíduo na sua esfera macro-social - ambiente em que se insere, características sócio-demográficas, grau de instrução - e a sua percepção quanto ao impacto da tecnologia nas condições de saúde, o empodera, integra e subsidia a participar ativamente das decisões das políticas públicas. Dessa forma, o retira da posição passiva e assimétrica de informação.

O acesso à informação é fundamental para o processo educativo do ser humano, fator determinante da saúde e que representa direito de acesso à formação pessoal. É componente essencial para o desenvolvimento físico, psicológico, social e espiritual da pessoa humana, e exige transparência e extensão da participação do cidadão. Assim, auxilia na formação do paciente do SUS, permite atrelar políticas bottom-up e top-down e estabelece nova forma de relação de cidadania.

Somente o acesso à informação poderá aprimorar as noções de cidadania e democracia da sociedade, visto que, segundo Aith (2007), é no seio de uma teoria (geralmente publicadas em revistas científicas) ou por meio da condução de novas investigações. 
ampliada de democracia que os direitos sociais podem ser repensados e os direitos políticos aprofundados. Ademais, de acordo com Habermas (1992), as formas de comunicação são primordiais para que a gênese do direito legítimo possa ser legalmente institucionalizada.

\section{Estudo de caso}

No Ministério da Saúde, a ATS é uma das atribuições do Departamento de Ciência e Tecnologia (DECIT), especificamente da Coordenação Geral de Avaliação de Tecnologias em Saúde, da Secretaria de Ciência, Tecnologia e Insumos Estratégicos, que conta com profissionais para a elaboração de informes baseados em evidência que apoiem a tomada de decisão.

Em 2011, a área recebeu uma demanda de um usuário do SUS que questionou a respeito do tratamento de artrite reumatoide; nas palavras: "Gostaria de saber se existe algum tratamento novo para a artrite reumatóide e se existem pesquisas ou remédios importados para testes no Brasil, pois a minha esposa é acometida da aludida doença" [sic].

Em atenção à manifestação, a área elaborou um informe, em linguagem clara, objetiva e acessível, em tempo hábil, com informações sobre a doença, os dados epidemiológicos, a abordagem terapêutica (tratamento medicamentoso e não medicamentoso) e o tratamento estabelecido no SUS, conforme protocolo. Destacaram-se os medicamentos disponíveis neste e os motivos pelos quais alguns registrados na Agência Nacional de Vigilância Sanitária ainda não estavam disponíveis. Nesse momento, justificou-se o atual processo de incorporação de tecnologias no sistema que, segundo a Lei $n^{\circ}$ 12.401/2011, prevê análises técnicas para identificação das opções terapêuticas que atendam às diretrizes: universalidade e integralidade com base no melhor conhecimento técnico-científico disponível; e proteção do cidadão por meio de processo seguro de incorporação de tecnologias relevantes para ele e para o sistema de saúde, por meio de parâmetros de eficácia, eficiência, efetividade e custo-efetividade.

Ressaltou-se, no texto, que o processo de incorporação de medicamentos e de alteração do protocolo é dinâmico e está sujeito ao surgimento de novos estudos que comprovem o benefício de um medicamento em comparação a outros. 
Pelo fato de a ATS respaldar-se em aspectos de eficácia, efetividade, segurança, acurácia, custo, custo-efetividade, éticos, culturais, ambientais e de equidade, coube à área técnica responder tal demanda. A considerar que a demanda proveio de um usuário do sistema, num cenário de assimetria informacional, buscouse atender tanto a dimensão ético-social da ATS quanto aos preceitos legais da LAI; o que corrobora a compreensão do homem da conjuntura em que está inserido.

Quanto às pesquisas, informaram-se aquelas financiadas pelo DECIT e como acessar a base que as contém (Pesquisa Saúde).

A área de ATS teve que se mobilizar para fornecer informações direcionadas ao usuário, fortalecendo seu papel de informá-lo a respeito do valor relativo das tecnologias com informações confiáveis e sólidas. Nesse contexto, a LAI, como instrumento oportuno de participação social, foi uma ferramenta capaz de direcionar a demanda, conferindo maior transparência ao processo.

\section{Conclusão}

O direito de acesso a informações aumenta as noções de cidadania, de boa governança, de eficiência da Administração Pública. Permite a fiscalização e o combate à corrupção, o desenvolvimento humano, a inclusão social e o êxito de outros direitos socioeconômicos, civis e políticos. Em nenhum país, o método democrático poder perdurar sem tornar-se um costume. Assim, o acesso à informação é fundamental para o processo educativo do ser humano, um fator determinante da saúde e que representa direito de acesso à formação pessoal.

Esse empoderamento do usuário, processo que reconhece o direito de participação nas decisões que afetam o cotidiano e promove espaços democráticos para o controle social das instituições, representa forma de participação popular premente, inclusive consoante com a ideologia da LAI. Assim, emergem renovada forma de cidadania e capacidade integrativa dos indivíduos, os quais, no contexto da saúde, estarão em posição de usuários das ações e serviços.

No sistema de saúde, a ATS é uma ferramenta que auxilia gestores e usuários a tomarem decisão por meio de informações sólidas e transparentes. Não se restringe apenas em determinar se uma tecnologia é eficaz e segura; preocupa-se com os aspectos econômicos e sociais na sua gestão. No Brasil, a visão social ainda é incipiente e deve ser objeto de reflexão e sensibilização dos atores governamentais. 
A publicação da LAl pode ser vista como uma oportunidade para efetivar a institucionalização do direito legítimo à informação.

\section{Agradecimentos}

As autoras agradecem a colaboração de Andressa Fracaro Cavalheiro e a Nashira Campos Vieira pelas contribuições ao trabalho.

\section{Referências}

AITH, F. Curso de Direito Sanitário. São Paulo: Quartier Latin, 2007.

ANGÉLICO, F. Lei de Acesso à Informação Pública e seus possíveis desdobramentos para a accountability democrática no Brasil. Dissertação (mestrado). São Paulo, Escola de Administração de Empresas de São Paulo da Fundação Getúlio Vargas, 2012. $133 p$.

ARTIGO19 BRASIL. Acesso à informação para a garantia de direitos humanos. Disponível em: http://artigo19.org/wp-content/uploads/2013/04/Acesso_ \%C3\%A0_informa\%C3\%A7\%C3\%A3o_para_a_garantia_de_direitos_humanos.pdf [data de consulta: 19 ago. 2012]

BOBBIO, N. O futuro da democracia: Uma defesa das regras do jogo. 5. ed. Rio de janeiro: Paz e Terra, 1992. $171 \mathrm{p}$.

BRASIL. Acesso à Informação Pública: Controladoria-Geral da União. Brasília, DF. Uma introdução à Lei 12.527, de 18 de novembro de 2011. Disponível em: http://www.cgu.gov.br/acessoainformacao/materiaisinteresse/cartilhaacessoainformacao.pdf [data da consulta: 19 ago. 2012].

BRASIL. Constituição da República Federativa do Brasil. Diário Oficial da União, Brasília, DF, 05 out. 1988.

BRASIL. Lei $n .^{\circ} 12527$, de 18 de novembro de 2011. Regula o acesso a informações previsto no inciso XXXIII do art. $5^{\circ}$, no inciso II do $\S 3^{\circ}$ do art. 37 e no $\S 2^{\circ}$ do art. 216 da Constituição Federal; altera a Lei no 8.112, de 11 de dezembro de 1990; revoga a Lei no 11.111, de 5 de maio de 2005, e dispositivos da Lei no 8.159, de 8 de janeiro de 1991; e dá outras providências. Diário Oficial da União, Brasília, DF, 18 nov. 2011.

CANELA, G.; NASCIMENTO, S. Acesso à informação e controle social das políticas públicas. Brasília: ANDI; Artigo 19, 2009.132 p.

DRUMMOND, M. et al. Key principles for the improved conduct of health technology assessments for resource allocation decisions. Int J Technol Assess Health Care, 24(3):244-58, 2008.

GABBAY J.; WALLEY T. Introducing new health interventions. British Medical Journal; 332:64-65, 2006

HABERMAS, J. Between Facts and Norms. Em: AITH, F. Curso de Direito Sanitário. São Paulo: Quartier Latin, 2007. 
HABERMAS, J. A inclusão do outro: estudos e teoria política. São Paulo: Loyola, 2002. 390 p.

INAHTA - The International Network of Agencies for Health Technology Assessment. Health Technology Assessment (HTA) Glossary. Disponível em: www.inahta.org

JONSSON E.; BANTA H.D. Management of health technologies: an international view. British Medical Journal, 319:1293, 1999.

KANT. Zum ewigen Frieden, Apêndice II. Em: BOBBIO, N. O futuro da democracia: Uma defesa das regras do jogo. 5. ed. Rio de janeiro: Paz e Terra, 1992. 171 p.

MORONI, J. Ao. Os cinco eixos do controle social. Em: CANELA, G.; NASCIMENTO, S. (orgs.) Acesso à informação e controle social das políticas públicas. Brasília: ANDI; Artigo 19, 2009. 132 p.

VELASCO-GARRIDO, M.; BUSSE, R. Health Technology Assessment: An Introduction on Objectives, Role of Evidence, and Structure in Europe - Policy Brief. European Observatory on Health Systems and Policies. Brussels: WHO European Centre for Health Policy, 2005. Disponível em: http://www.euro.who.int/_data/assets/pdf_file/0018/90432/E87866.pdf. [data da consulta: 26 ago. 2012]. 